\title{
Pure amnesia after unilateral left polar thalamic infarct: topographic and sequential neuropsychological and metabolic (PET) correlations
}

Stephanie Clarke, Gil Assal, Julien Bogousslavsky, Franco Regli, David W Townsend, Klaus L Leenders, Serge Blecic

\begin{abstract}
A 54-year-old patient who had an isolated small polar thalamic infarct and acute global amnesia with slight frontal type dysfunction but without other neurological dysfunction was studied. Memory improved partially within 8 months. At all stages the impairment was more severe for verbal than non-verbal memory. Autobiographic recollections and newly acquired information tended to be disorganised with respect to temporal order. Procedural memory was unaffected. Both emotional involvement and pleasure in reading were lost. On MRI, the infarct was limited to the left anterior thalamic nuclei and the adjacent mamillothalamic tract. The regional cerebral metabolic rate of glucose (measured with PET) was decreased on the left in the thalamus, amygdala, and posterior cingulate cortex 2 weeks after the infarct, and in the thalamus and posterior cingulate cortex 9 months later. These findings stress the specific role of the left anterior thalamic region in memory and confirm that longlasting amnesia from a thalamic lesion can occur without significant structural damage to the dorsomedial nucleus. Furthermore, they suggest that the anterior thalamic nuclei and possibly their connections with the posterior cingulate cortex play a role in emotional involvement linked to ipsilateral hemispheric functions.
\end{abstract}

$(\mathcal{F}$ Neurol Neurosurg Psychiatry 1994;57:27-34)

Lesions of the anterior and medial parts of the thalamus are often accompanied by memory dysfunction..$^{1-3}$ Bilateral lesions ${ }^{2-14}$ may produce major memory deficits that have sometimes been reported to last for several years. $^{245}$ Unilateral lesions may also be associated with memory dysfunction which is usually less severe and persistent and may be linked to a selective field of memory. ${ }^{215-22}$ In particular, verbal memory seems to be largely spared after right thalamic lesions. ${ }^{15-17}$ Conversely, preservation ${ }^{18} 19$ or relative sparing $^{20}$ of visuospatial memory after left thalamic lesions has been reported. The lateralisation of memory dysfunction is, however, not always present, and both right ${ }^{21}$ or left ${ }^{2,15,17,22}$ unilateral thalamic lesions have been reported with global amnesia.
Non-transient amnesia associated with unilateral infarct limited to the thalamus is uncommon. It usually involves the paramedian $^{181922-24}$ or polar ${ }^{152021}$ territory. We report clinical, topographical, and sequential neuropsychological and metabolic correlations in a patient with isolated infarct in the polar territory of the left thalamus.

\section{Case report}

The patient was a 54-year-old, right-handed woman of Spanish origin, married for 30 years, with no children, and living for the past 27 years in the French speaking part of Switzerland. She spoke French well and worked in semi-skilled employment.

From 7-23 July 1991, the patient and her husband visited their relatives in Spain. On their return flight, the plane passed through serious turbulence. At the time, the patient was greatly affected by this event. After her holiday, the patient returned to work and carried out her household tasks as usual. Waking on the morning of the fifteenth day after her return from Spain, the patient complained of seeing red. The following day, she became "strange", kept asking the date, was found walking in her flat apparently without purpose, and seemed to forget what she wanted to do. While cooking, she put a handful of salt into an omelette, apparently without knowing what she was doing. She was weeping and felt that she was not behaving as usual. Nevertheless, when her husband arrived at home she easily recognised him. She was admitted the same day to the neurology department. She was not drowsy. A detailed neurological examination was normal, including eye movements and motor and sensory functions.

A brain CT scan, performed 1 day after admission, showed a left anterior thalamic hypodensity; no other lesion was visible. MRI performed 5 days later showed a gadolinium enhancing lesion, $1.1 \mathrm{~cm}$ in diameter, in the anterior part of the left thalamus; this lesion was compatible with recent infarction (fig 1). When related to the map of thalamic nuclei, ${ }^{25}$ the lesion involved some of the anterior nuclei and the incoming part of the mamillothalamic tract, but spared most of the dorsomedian nucleus (fig 2). The localisation and extent of the lesions coincided with the territory of the polar (or tuberothalamic) artery. ${ }^{26}$ No other lesions could be seen. 
Figure 1 MRI of the thalamic region (phase T2), performed on the sixth day after the onset of the disease. Three

horizontal sections of the thalamus are shown, the lowest level on the left. The hyperdense lesion in the anterior part of the left thalamus was isodense in $T 1$ and took up gadolinium; it was compatible with a recent infarct in the territory of the left polar artery (for exact location see fig 2).
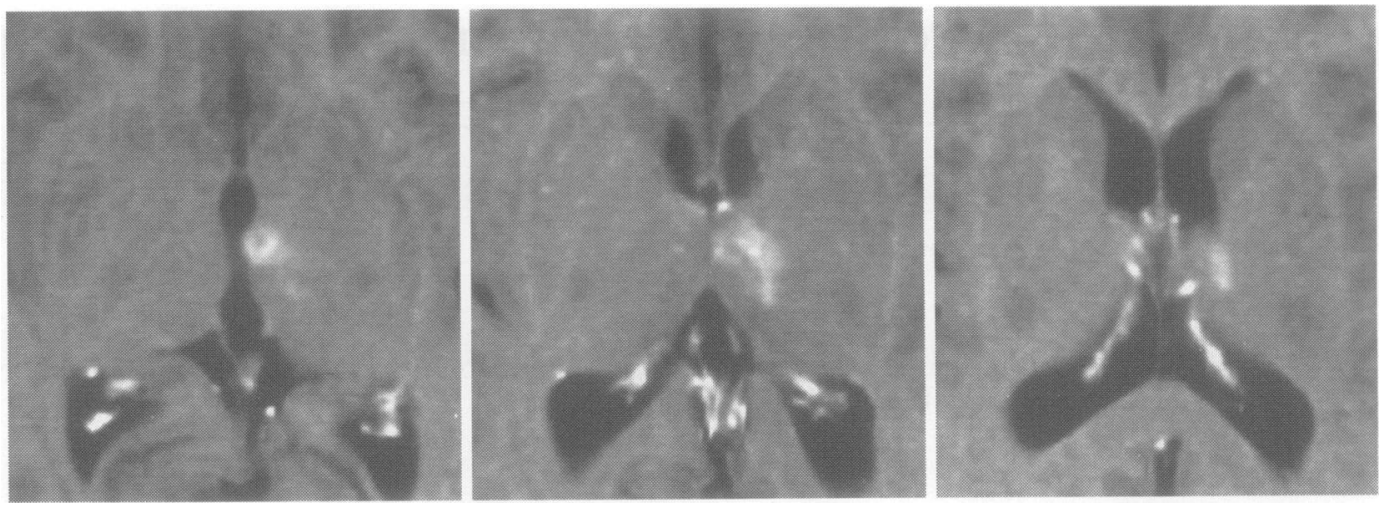

Figure 2 The infarct detected by MRI (fig 1) in relation to the thalamic nuclei. Horizontal sections through the inferior third (top) and the middle third (bottom) of the left human thalamus with the nuclear groups indicated according to Van Buren and Borke, ${ }^{25}$ the same nomenclature was used by von Cramon, et al. ${ }^{2}$ The extent of the (left) infarct is marked by a thick line. There was no extrathalamic damage.

The lesion spread over the anterior group of thalamic nuclei, the mamillo-

thalamic tract and the

internal medullary lamina.

The dorsomedial nucleus

was almost entirely spared.

Apr $=N$ anteroprincipalis

$\mathrm{Ca}=$ anterior commissure

Cemc $=N$ centralis

magnocellularis;

Cepc $=N$ centralis

parvocellularis;

Co = commissural nuclei;

$C p=$ posterior

commissure;

$D c=N$ dorsocaudalis;

$D o=N$ dorsooralis;

$F a=N$ fasciculosus;

$F=$ formix $H l=N$

habenularis lateralis;

$H m=N$ habenularis

medialis; $I M L=$ internal

medullary lamina;

Lpo = N lateropolaris;

$M=N$ medialis

(= dorsomedialis); $M T T$

= mamillothalamic tract;

$\mathrm{Pl}=$ pallidum laterale;

$P m=$ pallidum mediale;

Pma $=N$ paramedianus

anterior: $\operatorname{Pmp}=N$

paramedianus posterior;

$P_{t}=N$ parataenialis;

$P u=N$ pulvinaris;

Put = putamen;

$R=N$ reticularis

$T M=$ tractus Meynertii;

$V c e=N$ ventrocaudalis

externus; $V o e=N$

ventrooralis externus;

Voi $=N$ ventrooralis

internus.
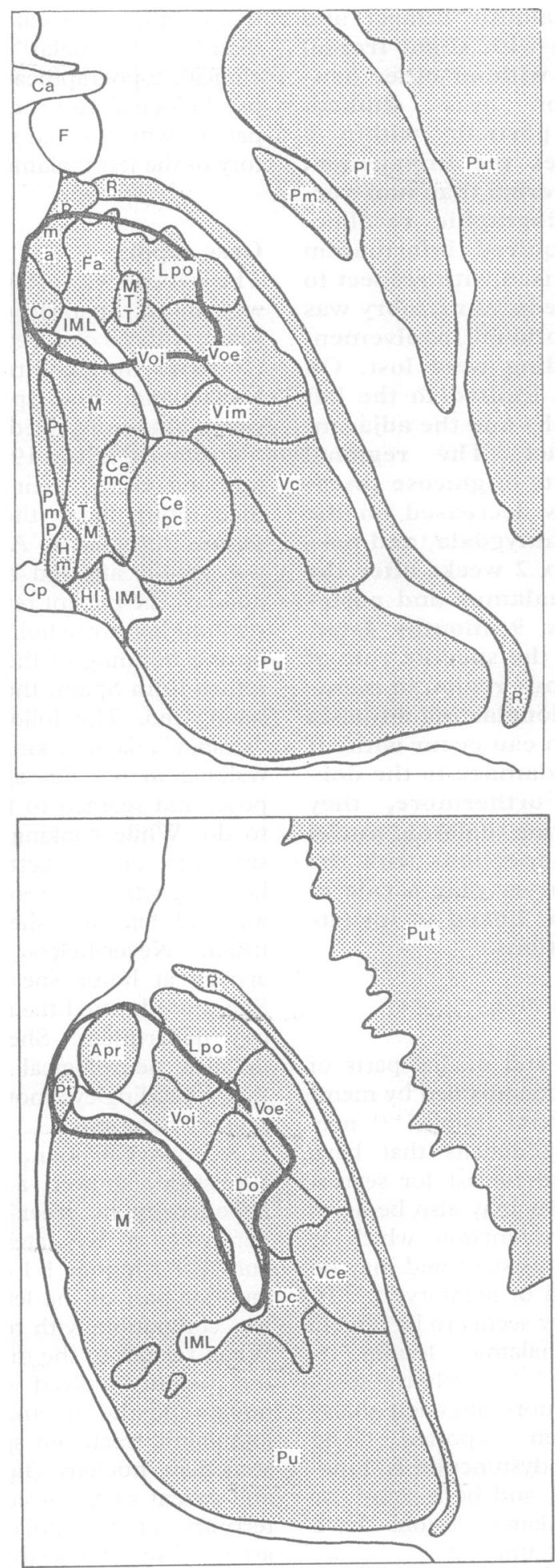

\section{Metabolic studies}

The regional cerebral glucose uptake was studied 15 days and 9 months after the onset of the illness using ${ }^{18} \mathrm{~F}$-fluorodeoxyglucose (FDG), and positron emission tomography (PET). The PET scanner, a prototype constructed by a research collaboration between Siemens/CTI (Knoxville, Tennessee) and Geneva University Hospital, ${ }^{27}$ used state of the art bismuth germanate block detectors and 31 transaxial sections of the brain were imaged simultaneously during a scan with a spatial resolution of $6-7 \mathrm{~mm}$. The thickness of each section was $3.4 \mathrm{~mm}$, covering a total of $10.8 \mathrm{~cm}$ of brain. The data were acquired and reconstructed using a SUN SparcStation computer with a fast SuperCard array processor attached. Subsequent image display and analysis of regions of interest was performed using ANALYZE software version 5.1 (Mayo Clinic, Rochester, MI, USA). In each session, approximately $7 \mathrm{mCi}$ of FDG were injected intravenously and arterialised venous blood (with the hand heated to $41^{\circ} \mathrm{C}$ ) was sampled at regular intervals throughout the study. The first study consisted of a single 40 minute acquisition commencing 45 minutes after injection. For the second study, dynamic scans of increasing duration (starting immediduration each) were performed during the 80 minutes post-injection (a total of 13 time frames were acquired). Attenuation correction factors were calculated using an ellipse approximation for the head. Glucose consumption rates $^{28}$ were estimated from the PET scans performed 45 minutes after injection, using a simple expression. ${ }^{29}$ At the time of the late scan, the ${ }^{18} \mathrm{~F}$ signal was assumed to come entirely from metabolised FDG which is irreversibly trapped. The regional cerebral glucose metabolic rate (rCMRGlu) is then:

\section{rCMRGlu $=\mathrm{Cg}$ Ctissue $(\mathrm{T}) /\left[\int \mathrm{dt} \mathrm{Cp}(\mathrm{t}) \mathrm{LC}\right]$}

where $\mathrm{Cg}$ is the (cold) plasma glucose concentration; Ctissue( $T$ ), the tissue concentration of FDG measured by the PET scan at time $\mathrm{T}$; $\int \mathrm{dt} \mathrm{Cp}(\mathrm{t})$, the radioactivity in the plasma integrated from the time of injection to time $\mathrm{T}$; and $\mathrm{LC}$, the lumped constant accounting for differences in membrane transport and phosphorylation between FDG and glucose (here $=0.42$ ). $T$ is the mid scan time. ately at injection with five scans of 75 second 

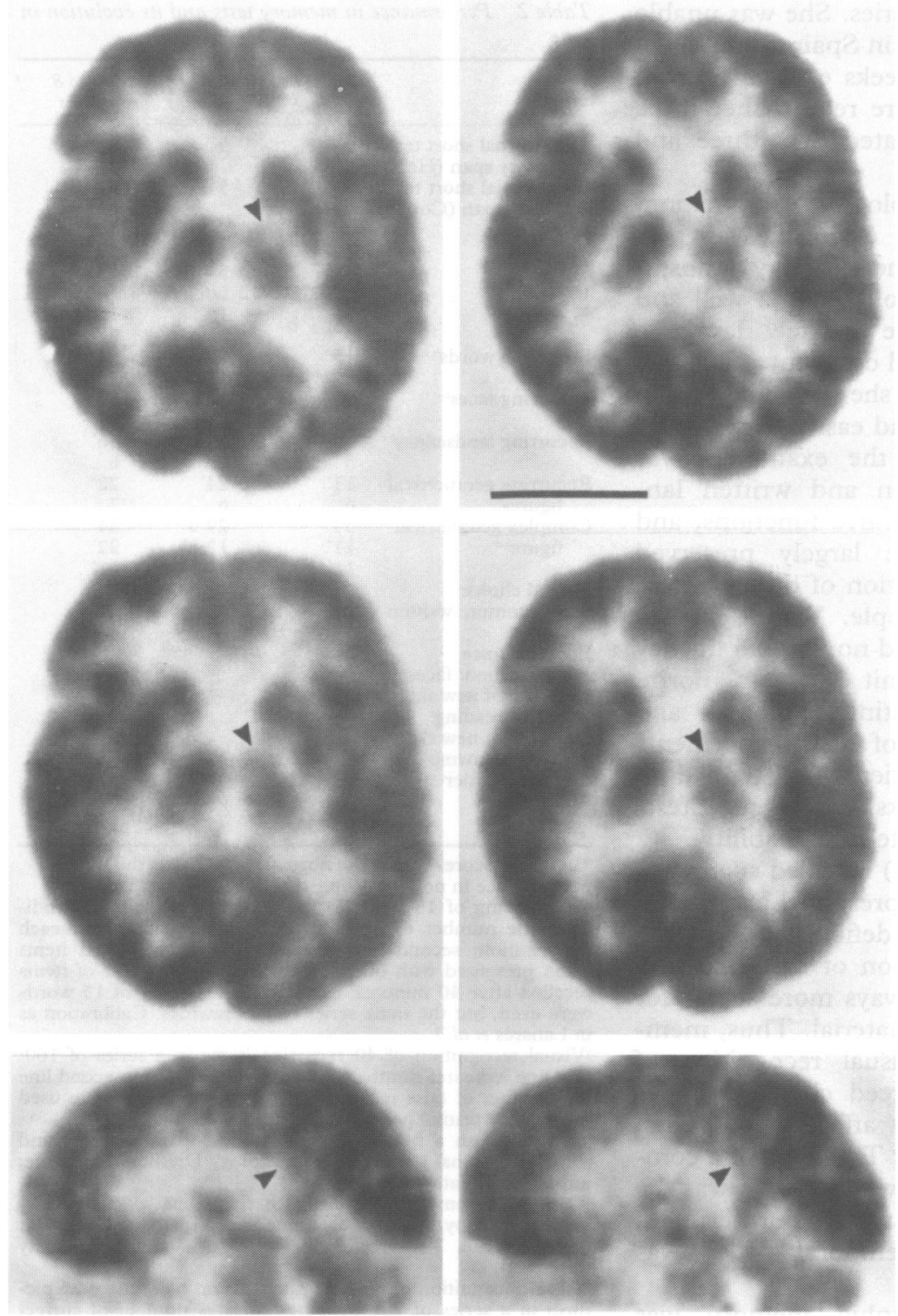

Figure 3 PET scans performed 45 minutes after the injection of FDG; the scale of grey represents glucose consumption estimates as explained in the text. Top row: two horizontal sections at the level of the thalamus from the first PET scan performed 15 days after the onset of the illness. Arrows point to the hypometabolic side in the left anterior thalamus. Left is to the right; bar $=5 \mathrm{~cm}$. Middle row: the corresponding sections at 9 months of evolution. The images in top and middle row have been co-registered; the data used in middle row have been sliced using the images of top row as the reference system..$^{56}$ Bottom row: parasagittal sections through the right (to the left) and the left cingulate cortex at 9 months of evolution. Arrows indicate the posterior part of the cingulate gyrus; note the relative hypometabolism on the left side.

Fifteen days after the onset of the illness, a significant ${ }^{\star}$ decrease in glucose metabolism was observed in several brain regions (fig 3 ). The average metabolic rate of the left thalamus was reduced by $10-20 \%$ compared with the right, and $30-32 \%$ in its anterior and anteromedial parts. Since the metabolic rate of the right thalamus $(36.2 \mu \mathrm{mol} / 100 \mathrm{ml} / \mathrm{min})$

\footnotetext{
ॠThirty one regions of interest were selected on horizontal or sagittal sections by comparison with the stereotaxic brain atlas. ${ }^{48}$ The regional cerebral metabolic rates of glucose were estimated according to the Sokoloff model, ${ }^{28}$ variability within the regions of interest has been evaluated. The left/right ratios of metabolic rates in symmetrically located regions of interest were calculated; they had a mean value of 0.90 with a $99 \%$ were calculated; they had a mean value of 0.90 with a $99 \%$ confidence interval of $\{0.832,0.971\}$ for the first scan and $0.94,\{0.891,0.995\}$ for the second scan. Thus, a left sided decrease of $17 \%$ or more on the first scan and of $11 \%$ or more on the second scan were statistically significant with
$\mathrm{p}<0.005$.
}

appeared normal when compared with a global rate for grey matter $(37 \cdot 1 \mu \mathrm{mol} /$ $100 \mathrm{ml} / \mathrm{min}$ ), the side difference was more compatible with left hypo- rather than right hyper-metabolism. No relative hypometabolism was observed in structures near to the left thalamus (caudate or putamen). Several regions known to be connected to the anterior or medial parts of the thalamus and/or involved in memory were analysed for left/ right metabolic differences. No major differences in glucose metabolism were observed in different parts of the frontal cortex or in the hippocampus. The metabolic rate in the lower part of the amygdala region was, however, $15 \%$ less on the left side compared with the right. The posterior half of the cingulate cortex (corresponding to Brodmann's areas 23 and lower 31) had a significantly lower metabolic rate, by $19 \%$, on the left than on the right side; no such difference was observed in the anterior half of the cingulate cortex. The metabolic asymmetry in the posterior half of the cingulate cortex was not accompanied by a similar asymmetry in the surrounding medial part of the occipitoparietal cortex nor in area 17 . Outside the cerebral hemispheres no marked side differences could be observed, except that the metabolism in the cerebellar hemisphere was lower on the right than on the left side.

The second metabolic study 9 months later showed a global rate for grey matter $(32.3 \mu \mathrm{mol} / 100 \mathrm{ml} / \mathrm{min})$ which was $13 \%$ lower than for the first scan, based on the same simplified estimation method. ${ }^{29}$ Similar decreases in glucose metabolism between two successive PET scans have been reported in normal volunteers. ${ }^{30}$ At the same level of significance $(p<0.005)$, the mean metabolic rate of the anterior and anteromedial regions of the thalamus was still lower (by 14-23\%) on the left side, but less so than in the first study $(30-32 \%)$. While the global rate decreased by $13 \%$ between the two scans, the left anterior superior region of the thalamus increased by $17 \cdot 3 \%$, and the same region in the right thalamus increased by only $3 \cdot 4 \%$. The same extrathalamic regions were measured and compared for left/right differences as in the first study. However, for this scan, no major differences were found between comparable regions on the right and left side, with the exception of the posterior cingulate cortex which remained significantly hypometabolic on the left side $(16.9 \%$ less on the left than on the right side; fig 3 ).

\section{Neuropsychological assessment} ACUTE PHASE

On her arrival in hospital, the patient could not tell the day, the month, or the year, but knew (correctly) that it was summer. She was roughly oriented in space. Sustained attention was affected; the patient was unable to recite the months in reverse, or to perform simple calculations. The most severe deficit concerned memory. The patient was unable to remember her profession, her date of birth, or 
to evoke other old memories. She was unable to remember her holiday in Spain from which she had returned two weeks earlier. From a list of 10 words that were read to her three times she correctly repeated two, three and three, respectively.

A careful neuropsychological examination, both in French and in Spanish, was performed from the 7th to the 19th day of hospitalisation. The patient collaborated well and was attentive. During the first few days, she was slow, easily tired, and disoriented in time, but she always knew that she was in a hospital and found her way around easily. Her behaviour and contact with the examiners was always adequate. Spoken and written language, praxias, visuocognitive functions, and spatial orientation were largely preserved (table 1), with the exception of difficulties in naming objects and people. Verbal fluency was severely deficient, and non-verbal fluency was at the lower limit of our norm. Programming of alternating sequences and reciprocal coordination of hand movements were impaired. The patient also tended to persevere in certain tasks. Intelligence tests revealed a low average intellectual ability.

Memory testing (table 2) revealed sparing of short term memory and preserved learning of new skills, but major deficits in episodic memory and in acquisition of new material. The latter deficit was always more severe for verbal than non-verbal material. Thus, memorising of 15 items, visual recognition of recurring items, and forced choice recognition were more severely affected for verbal than non-verbal material. The copy of a complex geometrical figure ${ }^{31}$ was good, as was the immediate and delayed recall. Furthermore, the memory of the temporal order was impaired.

Episodic and biographic memory was tested by extensively interviewing the patient and (separately) her husband on events that occurred during their married life. The two

Table 1 Performance in neuropsychological tests at given times after the onset of the symptoms.

\begin{tabular}{|c|c|c|c|}
\hline & 7 to 19 days & $\begin{array}{l}4 \text { to } 4 \cdot 5 \\
\text { months }\end{array}$ & $\begin{array}{l}7 \cdot 5 \text { to } 8 \\
\text { months }\end{array}$ \\
\hline Boston naming ${ }^{49}$ & $24 / 34$ & $27 / 34^{\circ}$ & $20 / 34^{*}$ \\
\hline Token te & - & $33 / 36^{\circ}$ & \\
\hline Farnsworth hues & - & - & good \\
\hline Topographical orientation & good & good & good \\
\hline Matching of unknown faces ${ }^{51}$ & - & good & - \\
\hline Hooper Visual Organization ${ }^{52}$ & $17 \cdot 5 / 20^{\circ}$ & & $18 / 20^{*}$ \\
\hline Columbia Visual Association & $8 / 12^{*}$ & $11 / 12^{*}$ & \\
\hline $\begin{array}{l}\text { Tactile recognition } \\
\text { Verbal fluency }{ }^{53}\end{array}$ & good & good & good \\
\hline letter "M" & 1 & $9^{*}$ & $14^{*}$ \\
\hline animals & 6 & 11 & $17^{\circ}$ \\
\hline Non-verbal fluency ${ }^{33}$ & & poor & poor \\
\hline Stroop $^{32}$ & slow & slow & slow \\
\hline Wisconsin card sorting ${ }^{33}$ & - & 2 series ${ }^{*}$ & \\
\hline Progressive Matrices $^{34}$ & - & $10^{*}$ & $12^{*}$ \\
\hline IQ total & 81 & - & 88 \\
\hline verbal & $\begin{array}{l}82 \\
83\end{array}$ & & $\begin{array}{l}91 \\
86\end{array}$ \\
\hline
\end{tabular}

Original versions of the tests or adaptations for French speaking population were used; references as listed in the paper.
For Wisconsin Card Sorting and the Progressive Matrices shortened versions have been used.

$\star$ Indicates scores within the normal range (determined on 420 normal subject of different age and socioprofessional group. ${ }^{53}$ ).
Table 2 Performance in memory tests and its evolution in time

\begin{tabular}{|c|c|c|c|}
\hline & 7 to 19 days & $\begin{array}{l}4 \text { to } 4 \cdot 5 \\
\text { months }\end{array}$ & $\begin{array}{l}7 \cdot 5 \text { to } 8 \\
\text { months }\end{array}$ \\
\hline $\begin{array}{l}\text { Audioverbal short term } \\
\text { memory span }\left(\mathrm{Hebb}^{54}\right)\end{array}$ & $6^{*}$ & $5^{*}$ & $6^{*}$ \\
\hline $\begin{array}{l}\text { Visuospatial short term } \\
\left.\text { memory span (Corsi }{ }^{54}\right)\end{array}$ & $6^{\circ}$ & $5^{*}$ & $5^{*}$ \\
\hline 15 words $^{\star}$ & $\begin{array}{l}3 / 5 / 4 / 1 / 7 \\
3 \\
0\end{array}$ & $\begin{array}{l}4 / 5 / 8 / 8 / 8 \\
13 \\
5\end{array}$ & $\begin{array}{l}3 / 4 / 6 / 5 / 6 \\
8 \\
1\end{array}$ \\
\hline 15 signs $^{2}$ & $\begin{array}{l}2 / 2 / 2 \cdot 5 / 2 \cdot 5 / 2 \\
15^{*} \\
3\end{array}$ & $\begin{array}{l}5 / 6 / 5 \cdot 5 / 6 / 6 \\
15^{*} \\
10 \cdot 5^{*}\end{array}$ & $\begin{array}{l}5 / 6 / 7 / 8 / 11 \\
15^{*} \\
9 \cdot 5^{\circ}\end{array}$ \\
\hline Recurring words ${ }^{\mathrm{b} c}$ & $\begin{array}{l}15 \\
6\end{array}$ & $\begin{array}{l}29 \\
10\end{array}$ & $\begin{array}{l}22 \\
4\end{array}$ \\
\hline Recurring faces ${ }^{b c}$ & $\begin{array}{l}38^{*} \\
3^{*}\end{array}$ & $\begin{array}{l}38^{*} \\
2^{*}\end{array}$ & $\begin{array}{l}37^{*} \\
9^{*}\end{array}$ \\
\hline Recurring landscapes ${ }^{b c}$ & $\begin{array}{l}30^{\circ} \\
5\end{array}$ & $\begin{array}{l}34^{*} \\
6\end{array}$ & $\begin{array}{l}36^{\circ} \\
6\end{array}$ \\
\hline $\begin{array}{l}\text { Recurring geometrical } \\
\text { figures }\end{array}$ & $\begin{array}{l}17^{\circ} \\
6\end{array}$ & $\begin{array}{l}24 \\
6\end{array}$ & $\begin{array}{l}22^{*} \\
7\end{array}$ \\
\hline $\begin{array}{l}\text { Complex geometrical } \\
\text { figure }^{\mathrm{d} d}\end{array}$ & $\begin{array}{l}34^{\circ} \\
11^{\circ} \\
11^{\circ}\end{array}$ & $\begin{array}{l}29 \cdot 5^{*} \\
12 \cdot 5^{*} \\
13 \cdot 5^{*}\end{array}$ & $\begin{array}{l}34^{*} \\
22^{*} \\
21^{*}\end{array}$ \\
\hline $\begin{array}{l}\text { Forced choice } \\
\text { recognition: written } \\
\text { words }^{c}\end{array}$ & $14 / 25$ & & \\
\hline $\begin{array}{l}\text { Forced choice } \\
\text { recognition: faces }\end{array}$ & $24 / 25^{*}$ & & \\
\hline $\begin{array}{l}\text { Learning of new skills: } \\
\text { mirror reading } \\
\text { Learning of new skills: }\end{array}$ & good & - & - \\
\hline mirror drawing & - & good & - \\
\hline Temporal order ${ }^{c}$ & $\begin{array}{l}38^{*} \\
0^{*} \\
63 \%\end{array}$ & $\begin{array}{l}44^{*} \\
0^{*} \\
74 \%\end{array}$ & $\begin{array}{l}42^{*} \\
0^{*} \\
71 \%\end{array}$ \\
\hline
\end{tabular}

^Indicates scores within the normal range. Note the superior performance in non-verbal tests.

"Memorising of 15 items in five repetitions ${ }^{55}$ : first line indicates the number of items repeated immediately after each presentation; second line, the number of recognised item when presented with others; third line, the number of items recalled after 40 minutes. Three different series of 15 words were used, but the same series of 15 drawings. Calibration as in Lanarès et al. ${ }^{5}$

bisual recognition of 40 recurring items in a series of 100 : first line indicates number of correct recognitions, second line the number of false recognitions. Same test series were used in the three testing periods.

'Calibrated on a normal population in function of age and socioprofessional level (Neuropsychology Division, Lausanne; unpublished data)

dComplex geometrical figure ${ }^{31}$; first line marks the performance at copy, second at immediate recall, and third at mance at copy, second at immediate recall, and third at
delayed recall. Three different figures of similar complexity

were used.
eVisual recognition of recurring items from two sets of 25 pictures in a series of 75: first line indicates number of correct recognitions, second line the number of false recognitions, and third line the percentage of correct attribution to the set (that is first or second one). Control population consisted of 20 normal subjects matched for age and socioprofessional level.

accounts were compared and the spontaneous and inquired memories of the patient were classified as (i) correct and precise (ii) vague or with imprecision in time; or (iii) wrong or impossible to evoke. The patient recalled well her early life and her wedding 30 years ago. Her major deficits concerned the year preceding her illness (fig 4). The memory of events that had occurred between the holiday in Spain and the onset of the illness was rather sparse in the personal domain, whereas some political events that had occurred during the same period were retained. More detailed recollections could be evoked from the stay in Spain and from both journeys. However, the memory of the temporal sequence of the events was often impaired. Details from the outward flight could be more easily evoked than those from the return flight, despite the dramatic passage through turbulence which marked the latter. Furthermore, a dissociation between memory of items and of the temporal order was apparent. While the patient was able to describe 


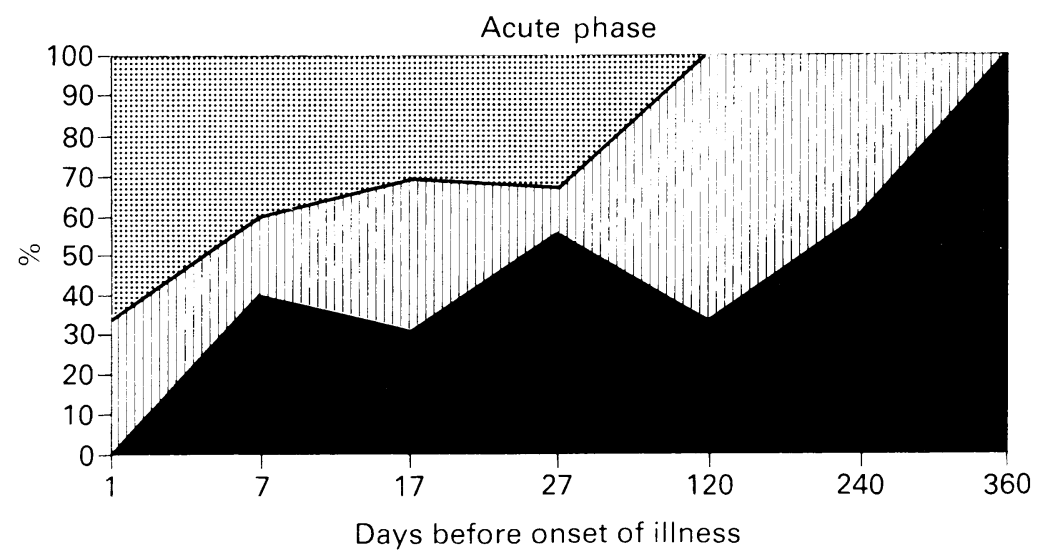

Figure 4 Autobiographical memory in the acute phase of the illness, tested as described in the text. The black surface represents the proportion of correct and easily revocable memories; hatched surface vague memories which were often incorrectly set in time; and dotted surface memories that were impossible to evoke. During the acute phase, 7 to 27 days before the onset of the illness corresponded to the patient's holidays; 120 days to a change in employment; about 240 days to the preceding Christmas and New Year; and about 360 days to the summer holidays the year before. Note that autobiographical memorv was more impaired for recent than for distant events.
FOUR MONTHS AFTER THE ONSET OF THE ILLNESS

After her return home, the patient adapted relatively well. She was well oriented in her flat, and did not experience difficulty in finding objects. She was able to do washing, ironing, and even complicated cooking tasks on her own. She believed she had changed her personality, becoming less kind than before the onset of her disease, and no longer trusted her emotional judgment of other people. She reported a curious change in her preferences. A very keen reader before her disease, she has now lost all pleasure in reading, and indeed read only very rarely, a change which was evident to the patient's family. Conversely, the patient now enjoyed watching televison much more than before her illness. She also reported difficulties in commencing different tasks and often felt a lack of motivation.

A detailed examination revealed good language functions (production, comprehension, repetition, denomination), good visual gnosias, and good visuoconstructive abilities (table 1). Verbal and non-verbal fluency remained poor. Reciprocal coordination of hand movements and movement sequences by the right hand were clumsy. The Stroop denomination ${ }^{32}$ was deficient because of slowness and naming errors. Tests of reasoning ${ }^{33} 3+$ were within normal limits. A test of sustained concentration was satisfactory, and reaction times to auditory and visual stimuli were within the normal range.

Memory was investigated with tests similar to those used in the acute phase (table 2). Some tests contained new, previously unused items, whereas others were presented for the second time containing the same items. The short term memory spans were within the normal range. The acquisition of new material was impaired, but more so for verbal than non-verbal material. The copying, immediate, and delayed recall of a complex geometrical figure (different specimen from previous one) were again good. The memory of the temporal order was now within the normal range. The patient was very vulnerable to distraction; a memory test containing an interference task (consonant trigrams) failed completely and provoked a panic reaction in the patient. Learning of new motor skills was preserved; the patient learnt readily to draw with the only visual control through a mirror.

Newly acquired autobiographic memory improved, but was far from excellent. During this testing period, the patient received a visit from her sister and they were both interviewed separately on their activities during this visit. The patient's recollections were correct in about $50 \%$ of the events recalled by her sister, $20 \%$ remained vague, and $30 \%$ were either wrong or impossible to evoke.

\section{EIGHT MONTHS AFTER THE ONSET OF THE}

ILLNESS

The patient was now able to lead an independent life, to fulfil her household obligations, and to have a satisfactory social life. 
Nevertheless, she experienced difficulties periodically. She felt sometimes unable to start certain activities. She was rather labile emotionally: on some occasions she was too emotive and on other, similar occasions, she felt an emotional "freeze". She returned to work for 3 half-days a week; although her performance was on the whole good, she had a few instances of complete "black-out". Typically, she would stand in front of a complex apparatus that she had used many times and could not remember what to do; there was no feeling of unfamiliarity. The loss of pleasure in reading persisted. The patient realised that she had become indifferent to choosing and buying clothes and shoes, which she enjoyed before her illness. She still could not remember the onset of her illness or much of the preceding holiday. However, she was able to differentiate between what she could remember herself and what she had been told later.

A detailed examination revealed good language functions, good visual gnosias, and good visuoconstructive abilities; functions known to be impaired in frontal lesions were within normal range (table 1). A test of sustained concentration was within the normal range. Performance on intelligence tests improved slightly and indicated average to low average intellectual ability.

Memory was investigated with tests similar to those used in the two previous evaluations (table 2). The performances were very much as they were 4 months previously. In particular, the verbal versus non-verbal dichotomy persisted. Furthermore, the patient was still vulnerable to distraction; an interference task (consonant trigrams) made memorising of simple items impossible.

\section{Discussion}

This patient had a sudden isolated memory disorder associated with a left polar thalamic infarct that was limited to the anterior group of thalamic nuclei, the incoming mamillothalamic tract, and the anterior part of the internal medullary lamina (fig 2). The dorsomedial nucleus was mostly spared, but was probably partially deafferented. The pathway from the amygdala to the dorsomedial nucleus is believed to be close to the mamillothalamic tract ${ }^{72}$ and was in this case likely to be damaged. The cortical afferents to the dorsomedian nucleus, however, should have been largely spared since they have been shown to arrive through the lateral, not the anterior, part of the thalamus. ${ }^{35}$

\section{METABOLIC CONSEQUENCES}

Large unilateral thalamocapsular lesions and unilateral lesions limited to the thalamus are often associated with a decrease in metabolic activity of the ipsilateral cortex. ${ }^{21} 3637$ In large lesions, this decrease concerns the whole ipsilateral cortex, and in smaller lesions there is a suggestion of a topographic relationship; anteromedial lesions being associated with more pronounced hypometabolism in the frontal cortex..$^{2136}$ Interestingly, a similar topographic relationship is not apparent after bilateral lesions; bilateral paramedian thalamic infarcts were reported to cause a (bilateral) diffuse cortical hypometabolism..$^{38}$

The small left anterothalamic infarction in our patient had fewer metabolic consequences. In the acute stage, 15 days after the infarction, the average metabolism was lower on the left than on the right side in the anterior part of the thalamus, the posterior half of the cingulate cortex, and the lower part of the amygdala. There were no major side differences in any part of the frontal cortex, the hippocampal formation, or the striatum. In the posterior part of the hemisphere, the decrease of metabolism was indeed limited to the cingulate cortex (probably Brodmann's area 23 and the lower part of 31); no decrease was observed in the medial parieto-occipital cortex. After 9 months of evolution, the hypometabolism persisted in the anterior part of the thalamus and in the posterior half of the cingulate cortex on the left side; side differences were no longer observed in the amygdala.

The hypometabolism in the ipsilateral posterior cingulate cortex can be well related to the lesion of anterior thalamic nuclei. Tracing studies in humans and in non-human primates have shown that these nuclei have their main cortical connections with the cingulate cortex (for review see Van Buren and Borke ${ }^{25}$ ). There is also evidence for a topographic relationship in these projections; in humans, lesions of the anterior cingulate gyrus caused retrograde degeneration in the anteroinferomedial part of the anterior nuclei, whereas lesions of the posterior cingulate cortex caused degeneration in the dorsolateral part. ${ }^{25}$

\section{THALAMIC AMNESIA}

The patient presented impairment in long term anterograde and retrograde memory, while short term memory (as assessed by spans) and procedural memory were preserved. Bilateral ${ }^{2-14}$ or unilateral right ${ }^{15-1721}$ or left $^{218-2022}$ anteromedial thalamic lesions have been reported to cause major deficits in long term anterograde memory, often accompanied by deficits in retrograde memory. Short term memory remained frequently within the normal, ${ }^{21-19} 22$ or lower normal ${ }^{21}$ range, although it was deficient following large lesions. ${ }^{24}$ When tested, procedural memory has been shown to be intact after unilateral ${ }^{19}$ and bilateral infarcts. ${ }^{7}$ Autobiographical memory has been reported to be either preserved $^{16} 19$ or impaired for recent events. ${ }^{2024}$

After an initial period of global amnesia, our patient performed consistently better on non-verbal than verbal material (table 2). This observation favours a moderate lateralisation in thalamic memory functions. It is in agreement with similar sparing of visuospatial memory that has been reported after left anterior $^{20}$ or paramedian ${ }^{1819}$ thalamic infarctions. Conversely, reports of largely spared verbal memory after right anterior ${ }^{15} 17$ or para- 
median $^{16}$ thalamic lesions further support such lateralisation. However, there are also reports of durable global amnesia - that is, a similar impairment in verbal and non-verbal memory, after left anterior ${ }^{21517}$ or paramedian $^{22}$ as well as right anterior ${ }^{21}$ thalamic infarcts. Two groups ${ }^{15} 17$ observed that left lesions disrupt both verbal and non-verbal memory, whereas right lesions almost selectively disrupt non-verbal memory. Thus, evidence for the lateralisation of thalamic memory functions is contradictory. Factors such as size of the lesion or handedness of the patient may play a role and need to be compared in a more reliable way between the studies.

After the patient partially recovered anterograde memory (see testing at 4 and 8 months after the onset of the illness) she remained extremely susceptible to interference during memorising tasks. This type of deficit has been reported after right anterior thalamic, ${ }^{21}$ left paramedian, ${ }^{1819}$ and bilateral paramedian $^{12}$ infarcts.

Temporal discrimination in anterograde and retrograde memory was impaired in our patient. Poor temporal discrimination in anterograde and retrograde memory is often present (and is a major symptom) in Korsakoff patients ${ }^{39} 40$ and after frontal lesions. ${ }^{4142}$ Past events are poorly dated following transient global amnesia. ${ }^{43} \mathrm{~A}$ left retrosplenial lesion has been reported to be associated with defective temporal discrimination for anterograde, but not for retrograde memory. ${ }^{44}$ Impaired chronological memory has not yet been associated with exclusively thalamic lesions. It is interesting that in our case poor temporal discrimination in memory has been associated with left anterior thalamic lesion and decreased metabolism in the ipsilateral posterior cingulate cortex. As described above, both structures are very likely to be interconnected and, as indicated by the case studied by Bowers et al, ${ }^{44}$ this circuit may play an important role in the temporal ordering of memories.

The performance profile of our patient resembles that described by Warrington and Weisskrantz, ${ }^{45}$ namely, bad performance on multiple choice recognition, yes/no recognition and story recall, defective memory of past events, and great vulnerability to interference contrasted by preserved skill learning and adequate access to semantic and phonological knowledge. They have considered this type of amnesia to be due to a disconnection between a hippocampotemporal system dealing with semantic memory, and a frontal system dealing with cognitive mediation (or associative retrieval). Both cerebral regions are known to be connected, either via the uncinate fasciculus or via the limbic circuit (temporal cortex-entorhinal cortex-parahippocampal region-hippocampus and subiculum-fornix-mamillary bodies-anterior and medial thalamus-frontal cortex). The limbic circuit has been demonstrated in nonhuman primates (for example, review by Amaral) ${ }^{46}$ and parts of it in humans (for review see Van Buren and Borke ${ }^{25}$ ). Very small thalamic lesions, on the right ${ }^{21}$ or on the left (the present paper), that were likely to disrupt selectively the hippocampo-mamillothalamo-frontal circuit, produced severe memory disorders. Our case supports further the important role of the disconnection between the temporal and frontal systems, since these systems seemed to function relatively normally by themselves, as suggested by the PET and neuropsychological studies.

CHANGES IN EMOTIONAL INVOLVEMENT

During the acute and chronic phase, our patient presented signs of frontal dysfunction, but less severe than those observed after paramedian thalamic infarcts. ${ }^{47}$ Several tests known to be impaired after frontal lesion were performed poorly during the first weeks of evolution but improved thereafter. No frontal-type behaviour was observed in everyday life or could be evoked during examinations beyond the first 10 days of evolution.

Significant changes occurred in the patient's preferences and, to some extent, also in her personality, both of which were noticed by the patient and by her family. The most important change was that she became emotionally labile, varying between an exaggerated sadness and tearfulness and emotional indifference. She was also prone to misunderstand the emotional content of her interactions with others. A lesser, but well confirmed, change was her loss of pleasure in reading that lasted throughout the follow up of 9 months. The patient read fluently and, 4 months after the onset of the illness, was able to recall a read story. Tests of sustained attention were then within normal limits. Thus, the loss of pleasure in reading was not due to difficulties in reading, attention, or remembering, but most likely to lack of emotional involvement in reading. This was confirmed by the patient's statements ("This does not mean anything to me emotionally"). The lack of emotional involvement was not generalised and did not include watching television, which was still experienced as pleasant. This means that not only memory but also emotional functions are likely to be lateralised.

The design and construction of the PET scanner was financially supported by the Swiss Commission for the Encouragement of Scientific Research (CERS), request number 1922.1 and by Siemens/CTI (Knoxville, TN, USA). We thank Dr R Woods and Dr Mazziotta from UCIA for Wermission to use their program to align the images shown in permission to use their program to align the images shown in gure 3. The co-gis performed at the MRC Cyclotron Unit, Hammersmith Hospital, London by Dr J Watson. We are grateful to Dr U Roelcke for participating in Bindschaedler for comments on the manuscript.

1 Bogousslavsky J, Regli F, Uske A. Thalamic infarcts: clinical syndromes, etiology, and prognosis Neurology 1988;38:837-48

2 Von Cramon DY, Hebel N, Schuri U. A contribution to the anatomical basis of thalamic amnesia. Brain the anatomical basis

3 Markowitsch HJ. Diencephalic amnesia: reorientation towards tracts? Brain Res Rev 1988;13:351-70

4 Rondot P, de Recondo J, Davous P, Bathien N, Coignet maux et amnésie durable. Rev Neurol (Paris) 1986;142: maux et am

5 Vighetto A, Confavreux C, Boisson D, Aimard G, Devic M. Paralysie de l'abaissement du regard et amnésie globale durables par lésion thalamo-sous-thalamique 
bilatérale Rev Neurol (Paris) 1986;142:449-55.

6 Gentilini M, de Renzi E, Crisi G. Bilateral paramedian thalamic artery infarcts: report of eight cases. $\mathcal{F}$ Neurol Neurosurg Psychiatry 1987;50:900-9.

7 Graff-Radford NR, Tranel D, Van Hoesen GW, Brand JP. Diencephalic amnesia. Brain 1990;113:1-25.

8 Barbizet J, Degos JD, Louarn F, Ngyen JP, Mas JL. Amnésie par lésion ischémique bi-thalamic. Rev Neurol (Paris) 1981;137:415-24.

9 Castaigne P, Lhermitte F, Buge A, Escourolle R, Hauw JJ, Lyon-Caen $O$. Paramedian thalamic and midbrain infarcts: clinical and neuropathological study. Ann Neurol 1981;10:127-48.

10 Schott B, Mauguière F, Laurent B, Serclerat O, Fischer C. L'amnésie thalamique. Rev Neurol (Paris) 1980 136:117-30.

11 Guberman A, Stuss D. The syndrome of bilateral paramedian thalamic infarction. Neurology 1983;33:540-6

12 Winocur G, Oxbury S, Roberts R, Agnetti V, Davis C Amnesia in a patient with bilateral lesions of the thalamus. Neuropsychologia 1984;22:123-43.

13 Bogousslavsky J, Regli F, Delaloye B, Delaloye-Bischof A, Assal G, Uske A. Loss of psychic self-activation with bithalamic infarction. Neurobehavioural, CT, MRI and SPECT correlates. Acta Neurol Scand 1991;83:309-16.

14 McEntee WJ, Biber MP, Perl DP, Benson DF, Diencephalic amnesia: a reappraisal. $\mathcal{f}$ Neurol Neurosurg Psychiatry 1976;39:436-41.

15 Graff-Radford NR, Eslinger PJ, Damasio AR, Yamada T Nonhemorrhagic infarction of the thalamus: behavioral, antomic, and physiologic correlates. Neurology anatomic, and

16 Speedie LJ, Heilman KM. Anterograde deficits for visuospatial material after infarction of the right thalamus. Arch Neurol 1983;40:183-6.

17 Bogousslavsky J, Regli F, Assal G. The syndrome of unilateral tuberothalamic artery territory infarction. Stroke 1986;17:434-41.

18 Speedie LJ, Heilman KM. Amnestic disturbance following infarction of the left dorsomedial nucleus of the thalamus. Neuropsychologia 1982;20:597-604.

19 Michel D, Laurent B, Foyatier N, Blanc A, Portafaix M. Infarctus thalamique paramédian gauche. Etude de la mémorie et du langage. Rev Neurol (Paris) 1982; 138:533-50.

20 Goldenberg G, Wimmer A, Maly J. Amnesic syndrome with a unilateral thalamic lesion: a case report. 7 Neurol 1983;229:79-86.

21 Rousseaux M, Kassiotis P, Signoret JL, Cabaret M, Petit $H$. Syndrome amnésique par infarctus restreint du thalamus antérieur droit. Rev Neurol (Paris) 1991;147: 809-18.

22 Gorelick PB, Amico LL, Ganellen R, Benevento LA. Transient global amnesia and thalamic infaretion Neurology 1988;38:496-9.

23 Squire LR, Moore RY. Dorsal thalamic lesion in a noted case of human memory dysfunction. Ann Neurol 1979;6:503-6.

24 Bogousslavsky J, Miklossy J, Deruaz JP, Regli F, Assal G. Unilateral left paramedian infarction of thalamus and midbrain: a clinico-pathological study. $\boldsymbol{f}$ Neurol Meurosurg Psychiatry 1986;49:686-94.

25 Van Buren JM, Borke RC. Variations and connections of the human thalamus. 1. The nuclei and cerebral connections of human thalamus. 1. The nuclei and cerebral connections of the human thalamus.

26 Percheron G. Les artères de thalamus humain. I. Artère et territoire thalamique polaires de l'artère communicante postérieure. Rev Neurol (Paris) 1976;132:297-307.

27 Townsend DW, Wensveen M, Byars $\mathrm{L}$, et al. A rotating PET camera using BGO block detectors. IEEE Medical Imaging Conference Record 1992;3:1658-62.

28 Sokoloff L, Reivitch M, Kennedy C, et al. The [14C]deoxyglucose method for the measurement of the local cerebral glucose utilisation: theory, procedure, and normal values in the conscious and anesthetized albino rat. $¥$ Neurochem 1977;28:897-916.

29 Rhodes CJ, Wise RJB, Gibbs JM, et al. In vivo disturbance of the oxidative metabolism of glucose in human cereof the oxidative metabolism of glucose in
bral gliomas. Ann Neurol 1982;12:614-26.

30 Tyler J, Strother SC, Zatorre RJ, et al. Stability of regional cerebral glucose metabolism in the normal regional cerebral glucose metabolism in the normal Nucl Med 1988;29:631-42.
31 Osterrieth PA. Le test de copie d'une figure complexe. Contribution à l'étude de la perception et de la mémoire. Arch Psychol 1945;30:205-3.

32 Stroop IR. Studies of interference in serial verbal reactions. F Exp Psychol 1945;18:643-62.

33 Berg EA. A simple objective test for measuring flexibility in thinking. $\mathcal{F}$ Gen Psychol 1948;39:15-22.

34 Raven JC. Guide to the standard progressive matrices. London: HK Lewis, 1958

35 Meyer M. A study of efferent connexions of the frontal lobe in the human brain after leucotomy. Brain 1949;72:263-96.

36 Baron JC, D'Antona R, Pantano P, Serdaru M, Samson Y, Bousser MG. Effects of thalamic stroke on energy metabolism of the cerebral cortex. A positron tomogrametabolism of the cerebral cortex. A positr

37 Franck G, Salmon E, Sadzot B, Van der Linden M. Etude hémodynamique et métabolique par tomographie à émission de positrons d'un cas d'atteinte ischémique thalamo-capsulaire droite. Rev Neurol (Paris) 1986;142: 475-9.

38 Lavasseur M, Baron JC, Sette G, et al. Brain energy metabolism in bilateral paramedian thalamic infarcts. Brain 1992;115:795-807.

39 Huppert FA, Piercy M. Recognition memory in amnesic patients: effects of temporal context and familiarity of material. Cortex 1976;12:3-20.

40 Meudell PR, Mayes AR, Ostergaard A, Pickering A. Recency and frequency judgements in alcoholic amnesics and normal people with poor memory. Cortex 1985;21:487-511.

41 Schimamura AP, Janowsky JS, Squire LR. Memory for the temporal order of events in patients with frontal lobe the temporal order of events in patients with frontal lobe lesions and

42 Milner B, Corsi P, Leonard G. Frontal lobe contribution to recency judgements. Neuropsychologia 1991;29: 601-18.

43 Hodges JR, Oxbury SM. Persistent memory impairment following transient global amnesia. F Clin Exp Neurol 1990;12:904-20.

44 Bowers D, Verfaellie M, Valenstein E, Heilman KM. Impaired acquisition of temporal information in retrosplenial amnesia. Brain and Cognition 1988;8:47-66.

45 Warrington EK, Weisskrantz L. Amnesia: a disconnection syndrome? Neuropsychologia 1982;20:233-48.

46 Amaral DG. Memory: anatomical organization of candidate brain regions. In: Mountcastle VB, et al, eds. date brain regions. In: Mountcastle VB, et al, eds. Handbook of physiology. The nervous system. Vol. 5 . Higher functions of the brain, Part 1. Bethesda,

47 Bogousslavsky J, Ferrazzini M, Regli F, Assal G, Tanabe $\mathrm{H}$, Delaloye-Bischof A. Manic delirium and frontal-like syndrome with paramedian infarction of the right thalamus. F Neurol Neurosurg Psychiatry 1988;51:116-9.

48 Talairach J, Tournoux P. Co-planar stereotaxic atlas of the human brain. New York: Thieme, 1988.

49 Thuillard Colombo F, Assal G. Adaptation française du test de dénomination de Boston-versions abrégées. Rev Eur Psychol Appl 1992;42:67-71.

50 de Renzi E, Faglioli P. Normative data and screening power of a shortened version of the token test. Cortex 1978;14:41-9.

51 Benton AL, Van Allen MW, Hamsher KdeS, Levin HS. Test of facial recognition, form SL. Stimulus and multiple choice pictures. Iowa City: Dept of Neurology; University choice pictures. Iowa City:

52 Hooper HE. Hooper visual organization test (VOT). Manual Los Angeles: Western Psychological Services, 1983.

53 Thuillard F, Assal G. Données neuropsychologiques chez le sujet agé normal. In: Habib $\mathrm{M}$, et al, eds. Démences et syndromes démentiels. Approche neuropsychologique. Paris: Masson, 1991:125-33.

54 Milner B. Interhemispheric differences in the localization of psychological processes in man. Br Med Bull 1971; 27:272-7

55 Lanarès J, Waeny AC, Assal G. Mémoire et spécialisation hémisphérique. Etude à partir d'une nouvelle épreuve. Rev Eur Psychol Appl 1987;37:13-25.

56 Wev Eur Psychol Appl 1987,37.13-25. A rapid automated algorithm for accurately aligning and reslicing positron emission tomography images. $\mathcal{f}$ Comput Assist Tomogr 1993;16:620-33. 